\title{
The Isolation and Characterization of Streptococcus mutans Serotype $h$ from Dental Plaque of Monkeys (Macaca fascicularis)
}

\author{
By DAVID BEIGHTON,* ROY R. B. RUSSELL AND \\ HAZEL HAYDAY \\ Royal College of Surgeons of England, Dental Research Unit, Downe, Orpington, \\ Kent BR6 7JJ
}

(Received 13 October 1980)

\begin{abstract}
A new serotype $(h)$ of Streptococcus mutans was isolated from the dental plaque of monkeys (Macaca fascicularis). Serotype $h$ strains fermented mannitol and melibiose but not sorbitol or raffinose, failed to hydrolyse aesculin and arginine, did not produce hydrogen peroxide and were unable to grow in the presence of bacitracin at 2 units $\mathrm{ml}^{-1}$. Sodium dodecyl sulphate-polyacrylamide gel electrophoresis of whole-cell proteins showed serotype $h$ strains to be closely related to strains of genetic group III (i.e. serotypes $d$ and $g$ ). The serotype-specific antigen of serotype $h$ contained glucose and galactose but was antigenically distinct from the polysaccharide antigens of serotypes $a, d$ and $g$. Serotype $h$ strains preferentially colonized developmental grooves of teeth and the proportion of serotype $h$ in the plaque flora was greater in monkeys fed a sucrose-rich diet than in monkeys fed a starch-based diet. A serotype $h$ strain was cariogenic for germ-free rats fed a high-sucrose diet, and serotype $h$ strains appear to be implicated in the caries process in monkeys.
\end{abstract}

\section{IN TRODUCTION}

Streptococcus mutans preferentially colonizes the pits and fissures of the occlusal surface of teeth (Ikeda \& Sandham, 1971) and it has been implicated as a major aetiological agent of dental caries in humans (Gibbons \& van Houte, 1975 $a$; Loesche \& Straffon, 1979) and in monkeys (Bowen, 1969; Colman \& Hayday, 1980). The species has been subdivided by a variety of taxonomic criteria. Seven serotypes have been described: five $(a, b, c, d$ and $e)$ by Bratthall (1970) and a further two ( $f$ and $g$ ) by Perch et al. (1974). On the basis of DNA guanine plus cytosine contents and inter-strain DNA homologies, Coykendall (1974) subdivided the species into four genetic groups. A similar grouping was obtained by Russell (1976), based on sodium dodecyl sulphate-polyacrylamide gel electrophoresis of whole cell proteins. Strains of $S$. mutans have also been classified according to their responses to biochemical tests (Perch et al., 1974; Shklair \& Keene, 1974). The latter authors defined five biotypes which generally conformed to the serotypes defined by Bratthall (1970).

Streptococcus mutans can be isolated infrequently from the dental plaque of monkeys fed starch-based diets but is regularly isolated from monkeys fed sucrose-supplemented diets (Cornick \& Bowen, 1972; Colman \& Hayday, 1980). We have been investigating changes in the streptococcal population in the plaque of monkeys fed sucrose-supplemented diets. These investigations have led to the isolation and characterization of streptococci unlike those previously isolated from the human oral cavity. This paper presents a description of one particular group of these streptococcal strains that we have identified as $S$. mutans on the basis of their biochemical characteristics and intra-oral distribution. Serological investigations showed that these streptococcal strains represent a new $S$. mutans serotype $(h)$, which is closely related to serotypes $d$ and $g$. 


\section{METHODS}

Isolation of streptococci from monkey dental plaque. Plaque from monkeys (Macaca fascicularis) fasted for at least $12 \mathrm{~h}$ was removed with a sterile scalpel blade, either from discrete sites or from many surfaces, depending on the experiment. The samples were placed in a glass/Teflon tissue grinder containing $2 \mathrm{ml}$ Thioglycollate medium without dextrose or indicator (Difco), and homogenized. The homogenates were serially diluted in the same medium and $0.1 \mathrm{ml}$ portions of suitable dilutions were spread in duplicate on a prereduced nonselective medium (Beighton \& Miller, 1977), on Mitis Salivarius agar (MS-agar; Oxoid), on MS-agar modified by the addition of 0.2 units bacitracin $\mathrm{ml}^{-1}$ and $15 \%(\mathrm{w} / \mathrm{v})$ sucrose (BMS-agar) Ito facilitate the isolation of $S$. mutans (Gold et al., 1973)|, or on TYC medium (Lab M, Salford, Lancs.). All inoculated plates were incubated for $2 \mathrm{~d}$ in an atmosphere consisting initially of $\mathrm{H}_{2} / \mathrm{CO}_{2}(90: 10, \mathrm{v} / \mathrm{v})$ in anaerobic jars fitted with Deoxy catalysts (Engelhard, Cinderford, Glos.).

The number of each colony type growing on each of the streptococcal selective media was counted and at least two representatives of each colony type were subcultured into Todd-Hewitt broth (Oxoid) for further identification. The total number of colonies growing on the nonselective medium was counted, enabling the number of each streptococcal species to be expressed as a percentage of a total bacterial count. However, these percentages are overestimates of the true proportion of streptococci in the plaque as not all the bacteria in monkey plaque will grow on the nonselective medium incubated anaerobically.

Biochemical tests. At least 20 representatives of the new type of isolate (see Results), each obtained from a different monkey, were examined in the following tests. Acid production from adonitol, arabinose, cellobiose, fructose, galactose, glucose, glycerol, glycogen, inositol, inulin, lactose, maltose, mannitol, mannose, melezitose, melibiose, raffinose, salicin, sorbitol, sorbose, sucrose, soluble starch, trehalose and xylitol was tested for by adding the substrate at $0.5 \%(\mathrm{w} / \mathrm{v})$ to a basal medium consisting of Thioglycollate medium without dextrose or indicator $\left(24 \mathrm{~g} \mathrm{l}^{-1}\right)$ and Purple broth base (Difco; $16 \mathrm{~g} \mathrm{l}^{-1}$ ). The ability of isolates to hydrolyse arginine was determined as described by Niven et al. (1942). Starch hydrolysis was tested for by streaking cultures on Brain-Heart Infusion agar (BHI-agar; Oxoid) plus $0.2 \%$ soluble starch, incubating in candle jars for $3 \mathrm{~d}$ and flooding the plates with Lugol's iodine (Cowan, 1974). The ability of isolates to hydrolyse aesculin and hippurate, to produce acetylmethylcarbinol from glucose and to produce catalase was determined as described by Cowan (1974). Ability to grow at $45^{\circ} \mathrm{C}$ was determined by streaking isolates on to plates of horse blood agar (HBA; Oxoid) and incubating in candle jars for $3 \mathrm{~d}$. Growth on agar containing $6.5 \%(\mathrm{w} / \mathrm{v}) \mathrm{NaCl}$, or $10 \%$ or $40 \%(\mathrm{w} / \mathrm{v})$ bile was tested for by appropriately supplementing BHI-agar and incubating the plates at $37^{\circ} \mathrm{C}$ for $3 \mathrm{~d}$ in candle jars. The ability to grow at $\mathrm{pH} 9.6$ was examined by inoculating $0.1 \mathrm{ml}$ of an $18 \mathrm{~h}$ Todd-Hewitt broth culture into $10 \mathrm{ml}$ Todd-Hewitt broth adjusted to $\mathrm{pH} 9.6$ and incubating at $37{ }^{\circ} \mathrm{C}$ for $3 \mathrm{~d}$. The effect of different atmospheres on growth was determined by streaking isolates on $\mathrm{HBA}$ plates and incubating in air, in candle jars under $\mathrm{CO}_{2}$, or anaerobically in an atmosphere of $\mathrm{H}_{2} / \mathrm{CO}_{2}(90: 10, \mathrm{v} / \mathrm{v})$. Hydrogen peroxide production was tested for using either an agar plate method (Colman, 1976) or by placing a peroxide test strip (Merck) into the bacteria pelleted from 20 $\mathrm{ml}$ Todd-Hewitt broth after growth for $48 \mathrm{~h}$ (G. Colman, personal communication). Bacitracin sensitivity was determined by streaking isolates on BMS-agar and by the method described by Shklair \& Keene (1974). Formation of intracellular polysaccharide was tested for by growing isolates for $3 \mathrm{~d}$ in candle jars on Todd-Hewitt agar supplemented with glucose $\left(20 \mathrm{~g} \mathrm{l}^{-1}\right)$ and then flooding the plates with Lugol's iodine to detect positive colonies (Cowan, 1974). Extracellular polysaccharide production was assessed by growing the organisms on TYC medium and MS-agar and in sucrose broth (Colman, 1976). Extracellular polysaccharides were precipitated by the addition of $1.2 \mathrm{vol}$. and $2.4 \mathrm{vol}$. ethanol to 0.1 dilutions of broth in $10 \%(\mathrm{w} / \mathrm{v})$ sodium acetate. The organisms were tested for the ability to form plaque on wires (McCabe et al., 1967) suspended in the sucrose broth. Terminal $\mathrm{pH}$ in glucose broth was measured after $18 \mathrm{~h}$ growth in $10 \mathrm{ml}$ volumes of broth containing (per litre): $10 \mathrm{~g}$ tryptone (Oxoid), $5 \mathrm{~g}$ yeast extract powder (Oxoid) and $10 \mathrm{~g}$ glucose. Dextranase production was tested for with Drug Sensitivity Test agar (Oxoid) supplemented with $0.5 \%(\mathrm{w} / \mathrm{v})$ Blue Dextran (Pharmacia). The plates were incubated in candle jars for $3 \mathrm{~d}$; dextranase activity was scored positive if colonies were surrounded by a clear halo. Fluoride sensitivity was determined by growing each of 10 isolates for $18 \mathrm{~h}$ at $37^{\circ} \mathrm{C}$ in duplicate $10 \mathrm{ml}$ volumes of Todd-Hewitt broth supplemented with glucose $\left(8 \mathrm{~g} \mathrm{l}^{-1}\right)$, with or without $0.26 \mathrm{mM}-\mathrm{NaF}$, and measuring the $A_{620}$. The $A_{620}$ of the fluoride-supplemented cultures was expressed as a percentage of that of the fluoride-free control culture. The ability of each of 10 isolates to grow at $\mathrm{pH} 5 \cdot 5$, relative to their ability to grow at $\mathrm{pH} 7 \cdot 0$, was determined by growing them for $18 \mathrm{~h}$ at $37^{\circ} \mathrm{C}$ in Todd-Hewitt broth plus glucose $\left(8 \mathrm{~g} \mathrm{I}^{-1}\right)$, adjusted to $\mathrm{pH} 5 \cdot 5$ with $\mathrm{HCl}$, and in similar broths adjusted to $\mathrm{pH} \mathrm{7.0.} \mathrm{The} A_{620}$ of the cultures at $\mathrm{pH} 5.5$ was expressed as a percentage of that of cultures at $\mathrm{pH} 7.0$ (Beighton \& Hayday, 1980).

Serological methods. Sera for typing were prepared by giving rabbits repeated injections of heat-killed bacteria as described by Bratthall (1969). Antisera were also raised against glucosyltransferase from $S$. mutans strain K1 (serotype $g$ ) prepared by methods described before (Russell, 1979 $a$ ) and against the wall-associated protein antigen B from strain Ingbritt (serotype $c$ ) as reported by Russell (1979b).

Immunodiffusion tests were performed using glass slides coated with $1 \%(\mathrm{w} / \mathrm{v})$ agarose in $0.05 \mathrm{M}$-Tris $/ \mathrm{HCl}$ buffer $(\mathrm{pH} \mathrm{7.5)}$. The sample wells, containing $20 \mu \mathrm{l}$, were $4 \mathrm{~mm}$ in diameter and $4 \mathrm{~mm}$ apart. For serotyping 
experiments, the antigen well contained a slurry of bacteria pelleted by centrifugation from an $18 \mathrm{~h}$ culture in $20 \mathrm{ml}$ Todd-Hewitt broth. Experience in our laboratory has shown that it is not necessary to carry out any form of extraction procedure in order to demonstrate the presence of the polysaccharide antigens of the $S$. mutans serotypes. Extracellular protein antigens were prepared by concentrating the filtrate of a culture grown in a semi-defined medium (Russell, $1979 c$ ) 100 -fold by precipitation with $65 \%$ saturated $\left(\mathrm{NH}_{4}\right)_{2} \mathrm{SO}_{4}$.

Polysaccharide antigen. The neutral polysaccharides from $S$. mutans AHT (serotype $a), \mathrm{B} 13(d), \mathrm{K} 1(g)$ and MFe28 $(h)$ were prepared by extraction with hot phenol (Westphal \& Jann, 1965) followed by dialysis of the aqueous phase to remove phenol, and removal of charged macromolecules with DEAE-cellulose (Whatman DE52). The sugar content of the polysaccharides was determined by hydrolysing samples in $3 \mathrm{M}-\mathrm{HCl}$ for $3 \mathrm{~h}$ at $105^{\circ} \mathrm{C}$, removing acid by evaporation and subjecting hydrolysates to thin-layer chromatography (Menzies \& Mount, 1975).

Sodium dodecyl sulphate (SDS)-gel electrophoresis. The protein compositions of different bacterial strains were compared by SDS-polyacrylamide gel electrophoresis (Russell, 1979d). Glucosyltransferase activity was detected on the gels after electrophoresis, by incubating them in sucrose in the presence of non-ionic detergent (Russell, 1979e).

Frequency of isolation of $S$. mutans serotype $h$ from monkeys. Plaque samples were collected from the caries-prone developmental grooves and occlusal surfaces of the molar teeth of 24 monkeys, aged from 9 to 20 months, that had consumed only a starch-based diet. The starch-based diet was fed to the young monkeys while they were with their mothers and for the time between weaning and the start of a caries-promoting regimen. The starch-based diet contained (in $4 \mathrm{l}$ water): $1920 \mathrm{~g}$ white sausage rusk (T. Lucas \& Co., Bristol), $720 \mathrm{~g}$ textured soya protein (T. Lucas \& Co.), $500 \mathrm{~g}$ binder (code 463-R.C.S., D.C.A. Industries, Aylesbury, Bucks.), $150 \mathrm{~g}$ gelatin (Croda Foods, Widnes, Cheshire), and $500 \mathrm{~g}$ SA37 (Intervet Laboratories, Cambridge). The mix was shaped into approximately 50 rissoles which were set by immersion in $5 \%(\mathrm{w} / \mathrm{v}) \mathrm{CaCl}_{2}$ solution. Each monkey received one rissole, half a peeled banana and half a shelled boiled egg each day. Plaque was also collected from a further 58 monkeys that had consumed a caries-promoting diet (Cohen \& Bowen, 1966) for up to 10 years. The plaque samples were processed as described above, and plated on MS-agar or TYC medium. The different streptococcal colonies growing on the media were identified and the frequency of isolation of serotype $h$ was calculated as a percentage of the total anaerobic plate colony count.

Intra-oral distribution of $S$. mutans serotype $h$. Plaque was collected from the caries-resistant buccal surface and from the caries-susceptible lingual developmental groove of the first right maxillary molar tooth of eight monkeys receiving a high-sucrose diet (BP Nutrition, U.K.). The tongue of each monkey was swabbed with a sterile alginate swab which was then dispersed in $2 \mathrm{ml}$ Thioglycollate medium without dextrose or indicator made up with Calgon-Ringer solution (Oxoid), contained in a glass/Teflon tissue grinder. The plaque samples and dispersed tongue swabbings were treated as described above and the proportion of $S$. mutans serotype $h$ at each site was calculated.

Influence of a high-sucrose diet on the percentage of $S$. mutans serotype $h$ in monkey plaque. Six monkeys were fed a starch-based maintenance diet for at least 5 months after weaning. Plaque samples were collected from the occlusal surfaces and developmental grooves of all the right maxillary molar teeth on the first day of the experiment and subsequently on days $14,30,36,53,78$ and 94 . On day 14 the diet was changed to a caries-promoting regimen (Cohen \& Bowen, 1966). The percentage of $S$. mutans serotype $h$ in each plaque sample was calculated as described above.

Induction of dental caries in rats. Twelve 21-d-old germ-free WAGG rats, housed in isolators at the Medical Research Laboratories, Animal Research Unit, Carshalton, were orally swabbed with an actively growing Todd-Hewitt broth culture of $S$. mutans $\mathrm{MFe} 28$ on three consecutive days. The rats were given a sterile caries-promoting diet (Grenby \& Hutchinson, 1969) and sterile distilled water for $21 \mathrm{~d}$. They were then killed by decapitation and the heads were taken back to the laboratory for microbiological and dental examinations. Swabs were taken of the oral cavity of each rat and plated on HBA plates. Organisms were isolated from the plates after $3 \mathrm{~d}$ anaerobic incubation. The teeth were examined for evidence of smooth surface caries (Keyes, 1958) and sectioned to enable the number of carious fissures to be determined (König et al., 1958). Previous investigations had shown that uninfected germ-free rats fed the caries-promoting diet for $42 \mathrm{~d}$ failed to develop dental caries.

\section{RES ULTS}

Isolation and biochemical characterization. The new serotype was originally identified as forming small, dark blue crinkled colonies up to $1 \mathrm{~mm}$ in diameter, with an erose edge, slightly pitting the agar but easily dislodged, though difficult to disperse, when grown on MS-agar. When grown on TYC medium it formed large white conical colonies 2 to $3 \mathrm{~mm}$ in diameter with an erose edge, surrounded by a distinctive white halo. The organism was rarely isolated on BMS-agar. 

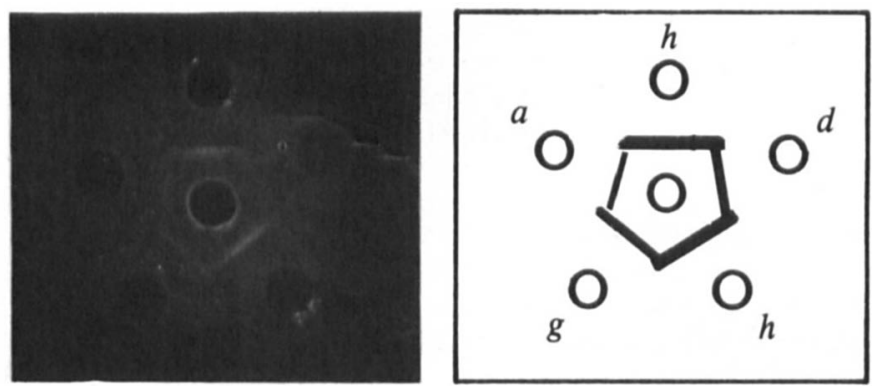

Fig. 1. Immunodiffusion of neutral polysaccharides from $S$. mutans strains of different serotypes, with antiserum to strain MFe28 (serotype $h$ ) in the centre well. The other strains used were AHT (serotype $a)$, B13 (d) and $\mathrm{K} 1(\mathrm{~g})$.

Acid was produced from glucose, sucrose, fructose, galactose, mannose, mannitol, melibiose, lactose, maltose, salicin, trehalose and inulin but not from adonitol, melezitose, sorbose, cellobiose, glycogen, soluble starch, inositol, xylitol, sorbitol, glycerol, arabinose or raffinose. Starch, aesculin and hippurate were not hydrolysed. Ammonia was not produced from arginine. No growth occurred at $45^{\circ} \mathrm{C}$, at $\mathrm{pH} 9.6$ or in the presence of $6.5 \% \mathrm{NaCl}$; growth was variable on agar with $10 \%$ or $40 \%$ bile added. Hydrogen peroxide and intracellular polysaccharide were not formed but acetylmethylcarbinol was produced from glucose. Colonies on plates incubated in candle jars under $\mathrm{CO}_{2}$ or anaerobically in $\mathrm{H}_{2} / \mathrm{CO}_{2}$ $(90: 10, \mathrm{v} / \mathrm{v})$ were larger than those on plates incubated in air. No cell-free, ethanolprecipitable polysaccharide was demonstrable in the sucrose broth, although colonies on sucrose-containing agar were adherent and in sucrose broths the organisms adhered tenaciously to the glass bottles, indicating the production of a sticky polymer from sucrose. The terminal $\mathrm{pH}$ in glucose-containing broth was 4.4 to 4.6 . When isolates were inoculated into broth initially at $\mathrm{pH} 5.5$ the final $A_{620}$ was $58 \pm 18 \%$ of that of cultures grown in broth initially at $\mathrm{pH} 7.0$. The organism was virtually resistant to $0.26 \mathrm{mM}-\mathrm{NaF}$, attaining $96 \pm 4 \%$ of the $A_{620}$ of cultures grown in $\mathrm{NaF}$-free broth.

Serological classification. Immunodiffusion experiments with strains of the new isolates showed that a major precipitin band was formed with typing sera prepared against strains of serotypes $a, d$ or $g$, but not with $b, c, e$ or $f$. Immunoelectrophoresis revealed that this antigen failed to migrate at $\mathrm{pH} \mathrm{7.5.} \mathrm{Acid} \mathrm{hydrolysis} \mathrm{of} \mathrm{the} \mathrm{polysaccharide,} \mathrm{followed} \mathrm{by} \mathrm{thin-layer}$ chromatography, revealed only glucose and galactose. From these preliminary results it appears that the major antigen bears a close resemblance to the specific antigens of serotypes $a, d$ and $g$, but is clearly antigenically distinct from them (Fig. 1). It was possible to produce a specific antiserum by absorbing antiserum raised against the new isolate MFe 28 with cells of B13 (serotype $d$ ), but only with considerable loss of titre. It is proposed that strains of the novel isolate be placed in the new serotype $h$, the serotype being defined by the polysaccharide antigen.

Several protein antigens are known to be common to serotypes $d$ and $g$. Concentrated culture filtrates of $\mathrm{MFe} 28$ or other serotype $h$ strains grown in a semi-defined medium contained protein antigens which gave precipitin lines of identity with glucosyltransferase and antigen B from $S$. mutans B13 (serotype $d$ ) or K1 (serotype $g$ ).

SDS-gel electrophoresis. Separation by SDS-polyacrylamide gel electrophoresis of the proteins extracted from strains of $S$. mutans allows their classification into groups corresponding to those delineated by studies of DNA homology (Russell, 1976). The serotype $h$ strain MFe28 had an electrophoretic pattern closely matching strains B 13 (serotype $d$ ) and K1 (g) (Fig. 2), and so can be placed in the genetic group III of Coykendall (1974). Twenty independent isolates of serotype $h$ strains were all found to give the same electrophoretic pattern. 


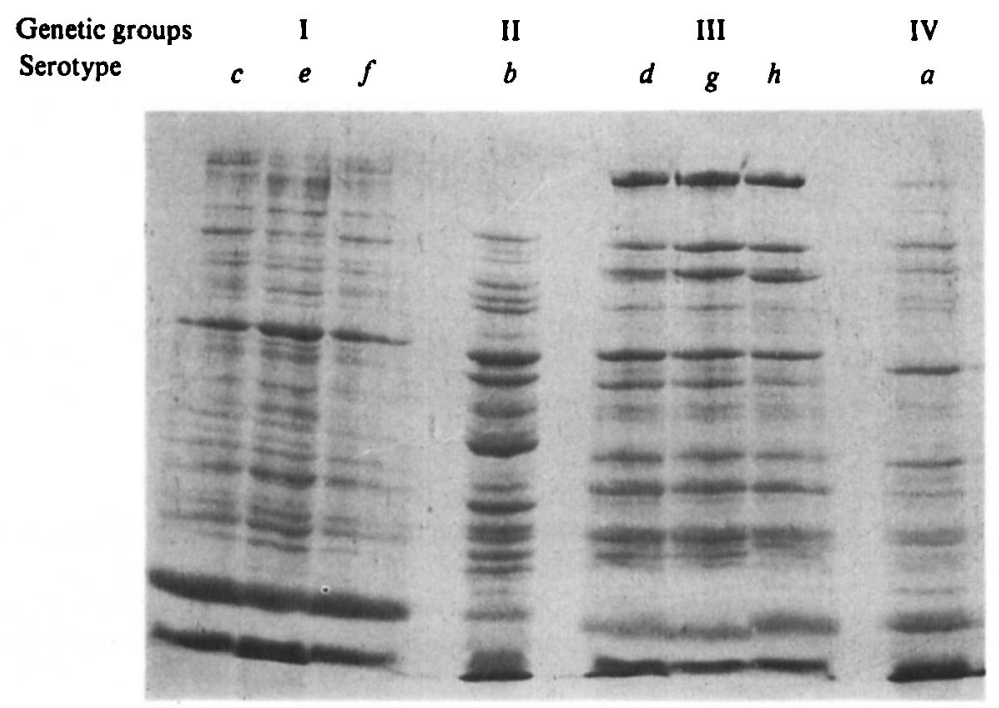

Fig. 2. SDS-polyacrylamide gel electrophoresis of proteins from $S$. mutans strains of different serotypes. The strains used were Ingbritt (serotype $c$ ), P4 $(e), 151(f), \mathrm{FA} 1(b), \mathrm{B} 13(d), \mathrm{K} 1(g), \mathrm{MFe} 28$ $(h)$ and AHT (a). Genetic groups I to IV are those of Coykendall (1974).

Glucosyltransferase. Serotype $h$ strains contain an antigen identical to the glucosyltransferase of serotype $d$ and $g$ strains (see above). Incubation of SDS-polyacrylamide gels in sucrose also showed bands of glucosyltransferase activity in serotype $h$ strains corresponding to those of serotypes $d$ and $g$. Although the presence of the enzyme was reflected in the 'rough' morphology of colonies on MS-agar and TYC medium, no ethanol-precipitable polysaccharide could be detected in the supernatants of cultures grown in sucrose broth. However, the isolates formed extensive plaques on wires. It is known that glucosyltransferase is generally cell-associated during growth in complex media containing traces of sucrose, but is free in the culture medium when synthetic media are used (Spinell \& Gibbons, 1974). When strain MFe28 was grown in a semi-defined medium, glucosyltransferase activity was located in the cell-free culture filtrate. Analysis of the products formed by incubation of such filtrates with sucrose using methods described previously (Russell, 1979a) showed $99 \%$ to be glucan (of which $73 \%$ was water-insoluble) and $1 \%$ fructan.

Frequency of isolation of $S$. mutans serotype $h$ from monkeys. Serotype $h$ strains were isolated from only 4 out of 24 monkeys consuming the starch-based diet. They were isolated from 37 out of 58 monkeys consuming the sucrose-rich diets.

Intra-oral distribution of $S$. mutans serotype $h$. At each of the tooth sites examined, the mean percentage of streptococci in plaque samples was $40 \%$ or greater. However, whereas in plaque samples from the buccal surface of the first permanent molar tooth the mean percentage of $S$. mutans serotype $h$ was $7.6 \%$, in samples from the lingual groove of the same tooth $S$. mutans serotype $h$ formed $41.2 \%$ of the total anaerobic count. None of the eight tongue swabbings yielded $S$. mutans serotype $h$ despite the finding that $77.3 \%$ of the total anaerobic plate count was identified as streptococci (Table 1).

Influence of a high-sucrose diet on the incidence of $S$. mutans serotype $h$ in monkey plaque. Streptococcus mutans serotype $h$ was not isolated from any of the six monkeys used in this experiment when they were fed the starch-based diet. Following the change in diet to the caries-promoting regimen the proportion of $S$. mutans serotype $h$ in the plaque slowly rose until it represented approximately $10 \%$ of the total anaerobic count (Table 2). 
Table 1. Intra-oral distribution of $S$. mutans serotype $h$

Site

Buccal surface of first permanent molar Lingual groove of first permanent molar Tongue

$\overbrace{\text { Total streptococci }}^{\text {Mean percentage of total anaerobic count }( \pm \text { S.E. })}$

$40 \cdot 0 \pm 9 \cdot 8$

$44.4 \pm 10.9$

$77.3 \pm 6 \cdot 8$
$7.6 \pm 4.8(5)^{*}$

$41 \cdot 2 \pm 12 \cdot 2(8)^{*}$

ND

ND, Not detected; detection level usually $<0.5 \%$.

* Numbers in parentheses indicate the number of samples, out of 8 , from which $S$. mutans serotype $h$ was isolated.

Table 2. Influence of a high-sucrose diet on the incidence of $S$. mutans serotype $h$ in pooled occlusal plaque of Macaca fascicularis

Plaque was collected from six monkeys that had been fed a starch-based diet for at least 5 months after weaning. On day 14 of the experiment the diet was changed to a sucrose-supplemented caries-promoting regimen.

\begin{tabular}{ccc}
\multirow{2}{*}{ Day } & $\begin{array}{c}\text { No. of monkeys } \\
\text { positive }\end{array}$ & $\begin{array}{c}\text { Mean percentage of total anaerobic } \\
\text { count }( \pm \text { s.E. })\end{array}$ \\
1 & 0 & ND \\
14 & 0 & ND \\
30 & 1 & $3 \cdot 0 \pm 3 \cdot 0$ \\
36 & 1 & $4 \cdot 1 \pm 4 \cdot 0$ \\
53 & 4 & $12 \cdot 7 \pm 5 \cdot 9$ \\
78 & 5 & $7 \cdot 8 \pm 3 \cdot 6$ \\
94 & 5 & $13 \cdot 2 \pm 4 \cdot 4$
\end{tabular}

ND, Not detected; detection level variable, though usually $<0.5 \%$.

Induction of dental caries. Dental caries was present on the smooth surfaces of the teeth of 6 of the 12 rats studied. In the $21 \mathrm{~d}$ test carried out the lesions did not penetrate the enamel and were restricted to the lingual surfaces of the first and second molar teeth. Fissure caries was detected in each rat and the mean number of carious fissures was $5 \cdot 1$ (s.D. 1.2; maximum possible score 12). The implanted organism was isolated from each of the infected germ-free rats.

It is difficult to assess the degree to which serotype $h$ strains are implicated in the caries process in monkeys, as usually other $S$. mutans serotypes are also present in the plaque. However, one monkey with $99 \%$ of its streptococcal flora as $S$. mutans serotype $h$ had twelve lesions in its primary dentition after consuming a caries-promoting diet (Cohen \& Bowen, 1966 ) for 12 months. No other $S$. mutans serotypes were isolated.

\section{DIS CUSSION}

The strains reported in this paper were identified as $S$. mutans on the basis of the fact that they produced acid from mannitol, produced glucans from sucrose, did not hydrolyse arginine or starch, produced acetylmethylcarbinol from glucose, did not produce hydrogen peroxide, tolerate $6.5 \% \mathrm{NaCl}$ or grow at $45^{\circ} \mathrm{C}$ (Clarke, 1924; Colman \& Williams, 1972; Facklam, 1977; Hardie \& Bowden, 1976) and preferentially colonized tooth surfaces (Gibbons \& van Houte, $1975 b$ ). Shklair \& Keene (1974) described a set of six tests by which strains of $S$. mutans could be assigned to five biotypes, though recently Hamada et al. (1979) have 
Table 3. Comparison of S. mutans serotype h (designated biotype VI) with other S. mutans biotypes

The data for biotypes I to V are from Shklair \& Keene (1974).

\begin{tabular}{|c|c|c|c|c|c|c|c|}
\hline \multirow[b]{2}{*}{ Biotype } & \multirow[b]{2}{*}{ Serotype } & \multicolumn{4}{|c|}{ Acid production from: } & \multirow{2}{*}{$\begin{array}{c}\mathrm{NH}_{3} \\
\text { from } \\
\text { arginine }\end{array}$} & \multirow{2}{*}{$\begin{array}{l}\text { Growth in } \\
\text { bacitrácin }\end{array}$} \\
\hline & & Mannitol & Sorbitol & Raffinose & Melibiose & & \\
\hline I & $c, e^{*}, f$ & + & + & + & $+^{*}$ & - & + \\
\hline II & $b$ & + & + & + & + & + & + \\
\hline III & $a$ & + & + & + & + & - & - \\
\hline IV & $d, g, \mathrm{SL}-1$ & + & $+1-$ & - & - & - & + \\
\hline V & $e$ & + & + & + & - & - & + \\
\hline VI & $h$ & + & - & - & + & - & - \\
\hline
\end{tabular}

suggested that strains of biotype $\mathrm{V}$ (serotype $e$, melibiose-negative strains) could not be reliably distinguished from strains of biotype I. Extending the scheme of Shklair \& Keene, serotype $h$ strains therefore represent biotype VI (Table 3 ). The new isolates could also be distinguished from other $S$. mutans strains by their possession of a unique polysaccharide antigen and therefore comprise a new $S$. mutans serotype: serotype $h$. Serotype $h$ strains showed a degree of cross-reactivity with serotypes $d$ and $g$ and to a lesser extent serotype $a$, though more detailed immunochemical studies will be necessary to elucidate the relationship of the serotype $h$ polysaccharide antigen to those of serotypes $a, d$ and $g$. The relatedness of serotype $h$ strains to members of genetic group III (Coykendall, 1974) was apparent from the presence of the same carbohydrates in the serotype-specific antigen (Linzer \& Slade, 1974; Iacono et al., 1975), the similar SDS-polyacrylamide gel electrophoresis patterns of whole cell proteins (Russell, 1976) and the similar growth patterns in the presence of $\mathrm{NaF}$ and in medium at pH 5.5 (Beighton \& Hayday, 1980).

The frequency of isolation and the proportion of $S$. mutans in plaque is influenced by the dietary sucrose level (Cornick \& Bowen, 1972; Colman \& Hayday, 1980). We found the isolation frequency of serotype $h$ strains to be very much higher in monkeys receiving sucrose-containing diets and demonstrated that the proportion of serotype $h$ strains in dental plaque increased in response to an increase in the level of dietary sucrose.

In humans, $S$. mutans strains are rarely isolated from tongue surfaces (Gibbons \& van Houte, $1975 b$ ); similarly, we could not isolate $S$. mutans serotype $h$ from the tongue of monkeys. The distribution of total streptococci on the tongue surface in dental plaque of monkeys resembles that found in humans (Socransky \& Manganiello, 1971). The distribution of serotype $h$ differed over the tooth surface, numbers being significantly greater in the developmental groove than on the buccal surface. This is similar to the findings of Ikeda \& Sandham (1971) for the distribution of $S$. mutans on different surfaces of the same tooth in humans and in monkeys (Colman \& Hayday, 1980).

The serotype $h$ strains differed from other strains of $S$. mutans in that they did not hydrolyse aesculin, produce acid from sorbitol, or produce hydrogen peroxide, and failed to form an ethanol-precipitable extracellular polysaccharide when grown in sucrose broth (Colman \& Williams, 1972). The latter negative results hindered the identification of these isolates as $S$. mutans but the demonstration of glucosyltransferase activity on electrophoresis gels enabled an identification to be made. This demonstrates the unreliability of the test for polysaccharide by ethanol precipitation (Hehre \& Neill, 1946) when applied to these isolates, and suggests that their ability to adhere to glass surfaces and to wires, or their colonial morphology, may be more reliable characteristics correlating with polysaccharide (glucan) production (Krasse, 1966). 
Strains resembling $S$. mutans serotype $h$ do not appear to have been isolated from other sources, which may be due to their bacitracin sensitivity precluding their isolation on BMS-agar (Gold et al., 1973), a characteristic they share with serotype $a$ strains (Little et al., 1977). However, it may be that for serotype $h$ strains monkey teeth are the principal habitat in the same way that serotype $b$ strains are primarily isolated from rat dentition and serotype $a$ strains from hamster teeth (Keyes, 1968).

Streptococcus mutans strain MFe28 has been deposited at the National Collection of Type Cultures (NCTC 11391).

This investigation was supported in part by the Medical Research Council.

\section{REFERENCES}

Beighton, D. \& Hayday, H. (1980). The effects of fluoride on the growth of oral streptococci. Microbios 27, 117-124.

Beighton, D. \& Miller, W. A. (1977). A microbiological study of normal flora of macropod dental plaque. Journal of Dental Research 56, 995-1000.

Bowen, W. H. (1969). A vaccine against dental caries. A pilot experiment with monkeys (Macaca irus). British Dental Journal 126, 159-160.

BRATTHALL, D. (1969). Immunodiffusion studies on the serological specificity of streptococci resembling Streptococcus mutans. Odontologisk revy 20, 231243.

Bratthall, D. (1970). Demonstration of five serological groups of streptococcal strains resembling Streptococcus mutans. Odontologisk revy $21,143-152$.

Clarke, J. K. (1924). On the bacterial factor in the aetiology of dental caries. British Journal of Experimental Pathology 5, 141-147.

Cohen, B. \& Bowen, W. H. (1966). Dental caries in experimental monkeys. British Dental Journal 121, 269-276.

Colman, G. (1976). The viridans streptococci. In Selected Topics in Clinical Bacteriology, pp. 179198. Edited by J. de Louvois. London: Baillière Tindall.

Colman, G. \& Hayday, H. (1980). A bacteriological study related to the onset of dental caries in monkeys (Macaca fascicularis). Caries Research 14, 285297.

Colman, G. \& Williams, R. E. O. (1972). Taxonomy of some human viridans streptococci. In Streptococci and Streptococcal Diseases, pp. 281299. Edited by L. Wannamaker \& J. M. Matson. London \& New York: Academic Press.

CoRnick, D. E. R. \& Bowen, W. H. (1972). The effect of sorbitol on the microbiology of dental plaque in monkeys (Macaca irus). Archives of Oral Biology 7 , 1637-1648.

Cowan, S. T. (1974). Cowan and Steel's Manual for the Identification of Medical Bacteria, 2nd edn. Cambridge: Cambridge University Press.

Coykendall, A. L. (1974). Four types of Streptococcus mutans based on their genetic, antigenic and biochemical characteristics. Journal of General Microbiology 83, 327-338.

FACKLAM, R. R. (1977). Physiological differentiation of viridans streptococci. Journal of Clinical Microbiology 5, 184-201.
Gibbons, R. J. \& van Houte, J. (1975a). Dental caries. Annual Review of Medicine 26, 121-136.

GibBons, R. J. \& VAN Houte, J. $(1975 b)$. Bacterial adherence in oral microbial ecology. Annual Review of Microbiology 29, 19-44.

Gold, O. G., Jordan, H. V. \& van Houte, J. (1973). A selective medium for Streptococcus mutans. Archives of Oral Biology 18, 1357-1364.

Grenby, T. H. \& Hutchinson, J. B. (1969). The effects of diets containing sucrose, glucose or fructose on experimental dental caries in two strains of rats. Archives of Oral Biology 14, 373-380.

Hamada, S., Masuda, N. \& Shimamoto, T. (1979). Some biological properties of Streptococcus mutans isolated from human mouths, with reference to the correlation with serotypes. Archives of Oral Biology 24, 627-631.

Hardie, J. M. \& Bowden, G. H. (1976). Physiological classification of oral viridans streptococci. Journal of Dental Research 55, A166-A176.

Hehre, E. J. \& Neill, J. M. (1946). Formation of serologically reactive dextran by streptococci from sub-acute bacterial endocarditis. Journal of Experimental Medicine 83, 147-163.

Iacono, V. J., Taubman, M. A., Smith, D. J. \& Levine, M. J. (1975). Isolation and immunochemical characterization of the group-specific antigen of Streptococcus mutans 6715. Infection and Immunity 11, 117-128.

IkedA, T. \& SANDhAM, H. J. (1971). Prevalence of Streptococcus mutans on various tooth surfaces in Negro children. Archives of Oral Biology 16, 1237-1240.

Keyes, P. H. (1958). Dental caries in molar teeth of rats, II. A method for diagnosing and scoring several types of lesions simultaneously. Journal of Dental Research 37, 1088-1099.

Keyes, P. H. (1968). Similarities and differences in dental caries in various species. In Art and Science of Dental Caries Research, pp. 185-199. Edited by R. S. Harris. New York: Academic Press.

König, K. G., Marthaler, T. M. \& MühlemanN, H. R. (1958). Methodik der kurzfristigerzeugten Rattenkaries. Deutsche Zahn-, Mund- und Kieferheilkunde 29, 99-127.

Krasse, B. C. (1966). Human streptococci and experimental caries in hamsters. Archives of Oral Biology 11, 429-436.

Linzer, R. \& Slade, H. D. (1974). Purification and characterization of Streptococcus mutans group $d$ 
cell wall polysaccharide antigen. Infection and Immunity 10, 361-368.

Little, W. A., Korts, D. C., Thomson, L. A. \& Bowen, W. H. (1977). Comparative recovery of Streptococcus mutans on ten isolation media. Journal of Clinical Microbiology 5, 578-583.

Loesche, W. J. \& Straffon, L. H. (1979). Longitudinal investigation of the role of Streptococcus mutans in human fissure decay. Infection and Immunity 26, 498-507.

McCABe, R. M., Keyes, P. H. \& Howell, A. (1967). An in vitro method for assessing the plaque forming ability of oral bacteria. Archives of Oral Biology 12, 1653-1656.

Menzies, I. S. \& Mount, J. N. (1975). Advantages of silica gel as a medium for rapid thin-layer chromatography of neutral sugars. Medical Laboratory Technology 32, 269-276.

Niven, C. F., JR, Smiley, K. L. \& Sherman, J. M. (1942). The hydrolysis of arginine by streptococci. Journal of Bacteriology 43, 651-660.

Perch, B., KJems, E. \& Ravn, T. (1974). Biochemical and serological properties of Streptococcus mutans from various human and animal sources. Acta pathologica et microbiologica scandinavica $\mathbf{B 8 2}$, 357-370.

Russell, R. R. B. (1976). Classification of Streptococcus mutans strains by SDS gel electrophoresis. Microbios Letters 2, 55-59.

Russell, R. R. B. $(1979 a)$. Glucosyltransferases of
Streptococcus mutans strain Ingbritt. Microbios 23, 135-146.

Russell, R. R. B. $(1979 b)$. Wall-associated protein antigens of Streptococcus mutans. Journal of General Microbiology 114, 109-115.

Russell, R. R. B. $(1979 c)$. Purification of Streptococcus mutans glucosyltransferase by polyethylene glycol precipitation. FEMS Microbiology Letters 6, 197-199.

Russell, R. R. B. $(1979 d)$. Comparison of oral Streptococcus mutans AHT with strains of serotypes $a$ and $g$ by biochemical and electrophoretic methods. Archives of Oral Biology 24, 617-619.

Russell, R. R. B. $(1979 e)$. Use of Triton X-100 to overcome the inhibition of fructosyltransferase by SDS. Analytical Biochemistry 97, 173-175.

Shrlair, I. L. \& KEENE, M. J. (1974). A biochemical scheme for the separation of the five varieties of Streptococcus mutans. Archives of Oral Biology 19, 1079-1081.

Socransky, S. S. \& Manganiello, A. D. (1971). The oral microbiota of man from birth to senility. Journal of Periodontology 42, 485-496.

SpINELl, D. M. \& GibBons, R. J. (1974). Influence of culture medium on the glucosyltransferase and dextran-binding capacity of Streptococcus mutans 6715 cells. Infection and Immunity 10, 1448-1451.

WestPhaL, O. \& JANN, K. (1965). Bacterial lipopolysaccharide extraction with phenol-water and further applications of the procedure. Methods in Carbohydrate Chemistry 5, 83-91. 